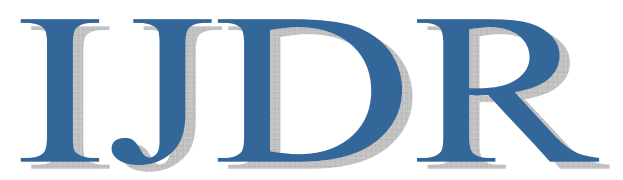

International Journal of Development Research

Vol. 10, Issue, 06, pp. 37247-37252, June, 2020

https://doi.org/10.37118/ijdr.19119.06.2020

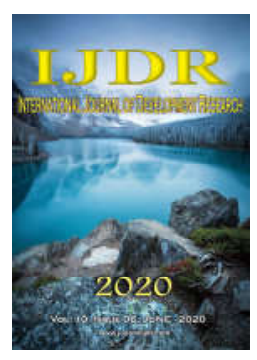

\title{
TECHNOLOGIES AND NEWS: CASE STUDY ON IMPLICATIONS TECHNIQUES FOR THE APPLICATION OF A SPIRAL MIXER IN THE BAKING PROCESS IN MANAUS-AM
}

\author{
${ }^{1}$ Matheus Torres Pinto, ${ }^{1}$ Elias Rufino de Lima, ${ }^{1}$ Aristeu Souza da Fonseca, ${ }^{1}$ Livia da Silva \\ Oliveira and ${ }^{* 2}$ David Barbosa de Alencar
}

\author{
${ }^{1}$ Academic Department, University Center FAMETRO, Amazon-Brazil \\ 2Institute of Technology and Education Galileo of Amazon (ITEGAM), Brazil
}

\section{ARTICLE INFO}

Article History:

Received $11^{\text {th }}$ March, 2020

Received in revised form

$16^{\text {th }}$ April, 2020

Accepted $03^{\text {rd }}$ May, 2020

Published online $30^{\text {th }}$ June, 2020

Key Words:

Technology; Kneader; Spiral; Bread making; Trade.

*Corresponding author:

David Barbosa de Alencar,

\begin{abstract}
Technologies are conditions for positive changes in the environment of industry, services, commerce and others. The implementation of new technologies requires adaptations for the insertion of mechanisms capable of increasing the efficiency of the sector, improving the quality of the product, improving the training of professionals, as well as structuring effective improvements in the system. In the universe of options for framing changes, an impact study for the insertion of technological bases must be made, otherwise, it may bring loss in planned investment in a certain application view. This work addresses the implementation of hygiene and the regulatory standard in the spiral mixer, estimating to validate the safety and quality parameters for the proper installation of the kneader, which because of the adequacy of the minimum standards of hygiene and safety. The methodology applied in the study, which is configured as a case study, whose guiding aspect is the observation and description of the rules for the allocation of adequate conditions for the device to work within the necessary standards. The expectation of the studies carried out in this work is to clarify the rules and the adaptation of the points to bring together the inclusion of technology within the limitations in the application environment. The study is carried out in a commercial environment in the City of Manaus.
\end{abstract}

Copyright (C) 2020, Matheus Torres Pinto et al. This is an open access article distributed under the Creative Commons Attribution License, which permits unrestricted use, distribution, and reproduction in any medium, provided the original work is properly cited.

Citation: Matheus Torres Pinto, Elias Rufino de Lima, Aristeu Souza da Fonseca, Livia da Silva Oliveira and David Barbosa de Alencar. "Technologies and news: case study on implications techniques for the application of a spiral mixer in the baking process in manaus-am", International Journal of Development Research, 10, (06), 37247-37252.

\section{INTRODUCTION}

The automation and qualification of manufacturing systems is a necessity of modern society, there is no more way to think about an industry, whatever the segment, it needs to emancipate itself from the difficulties that interrupt or make work and creation systems obsolete or very conservative and outside the context of market innovation. Since the first records of the presence of bread as a staple food, about 10,000 years ago, we can talk about equipment and utensils used in rudimentary productions, that is, in technologies that have evolved over time. However, at no previous time have technological advances been as fast as in the contemporary era. These advances constantly promote innovation in terms of equipment and utensils, which reach the market more and more sophisticated, enabling increasingly mechanized processes. As stated by Sebess (2011, p.24), Bakery Sector.
Growth in the bakery sector today is of fundamental importance. With the use of the spiral kneader in the bread making process, we stopped using the artisanal process still very used in this segment, the use modern equipment always aiming to maintain greater productivity with quality. meeting the satisfaction of our customers, who are more demanding every day, in a satisfactory scope. In the contemporary world, according to Cuponi (2016), technology is a notorious, important part, and can mean both the satisfaction with the devices that make life more comfortable, the enthusiasm for the possibilities that the computer and the Internet has, as for the fear of increasingly powerful and sophisticated weapons or our perplexity at the cloning of organisms. Technology is important, as it implies a systematic and lasting aspect, which must be exercised at the service of people and not people enslaved by technology. This work brings the perspective of implementing the adaptation of hygiene conditions and 
updates, making use of the regulatory standard that governs the installations of the spiral kneading machine in a medium-sized bakery. What is sought with this study is to implement improvements, according to NBR 15734, adapting the machine to health and safety conditions. Because it is a machine that was available to the system, but its operation was prevented from working because it did not meet the minimum hygiene and safety requirements. The methodology of this study is characterized as applied scientific, because it is about implementations of improvements in a productive bakery system.

\section{BIBLIOGRAPHIC REFERENCE}

Characterization of the Spiral Kneader: It consists of a machine capable of preparing all types of bread dough with homogeneity and oxygenation. Depending on the model, it can have a digital timer, allowing the operator to perform other parallel tasks. The beater and pan are activated by a single command, it is characteristic the presence of sensors and safety buttons for immediate stop in an emergency (PERFECTA, 2019). The spiral kneading machine is a device that amplifies the manufacturing process in the manufacture of breads and other systems that require homogeneity and oxygenation. The models and formats vary according to the manufacturer. Figure 1 highlights the specification of a perfecta spiral kneader.

\begin{tabular}{|c|c|c|}
\hline \multicolumn{3}{|c|}{ TECHNICAL DATA } \\
\hline Code & \multicolumn{2}{|c|}{ 188BRE126HC/ 188BRE136HC } \\
\hline Wattage & \multicolumn{2}{|c|}{$3,7 \mathrm{~kW} 1 / 6,0 \mathrm{~kW} 2$} \\
\hline Power Supply & \multicolumn{2}{|l|}{ Three-phase } \\
\hline Tension & $220 \mathrm{~V} 60 \mathrm{~Hz}$ & $380 \mathrm{~V} 60 \mathrm{~Hz}$ \\
\hline Chain & $21,11 / 20,3 \mathrm{~A} 2$ & $12,21 / 11,8 \mathrm{~A} 2$ \\
\hline Capacity & \multicolumn{2}{|c|}{$80 \mathrm{~kg}$ mass $/ 50 \mathrm{~kg}$ of flour } \\
\hline Height & \multicolumn{2}{|l|}{$1490 \mathrm{~mm}(1,49 \mathrm{~m})$} \\
\hline Width & \multicolumn{2}{|l|}{$730 \mathrm{~mm}(0,73 \mathrm{~m})$} \\
\hline Depth & \multicolumn{2}{|l|}{$1460 \mathrm{~mm}(1,46 \mathrm{~m})$} \\
\hline Weight & \multicolumn{2}{|l|}{$516 \mathrm{~kg}$} \\
\hline ROTATIONS & Pot & Beater \\
\hline Speed (Low) & $15 \mathrm{rpm}$ & $111 \mathrm{rpm}$ \\
\hline Speed (High) & $30 \mathrm{rpm}$ & $222 \mathrm{rpm}$ \\
\hline
\end{tabular}

Source: Perfecta (2020) - Adapted.

\section{Fig. 1. Technical specification of a spiral kneader}

For the spiral kneader, the mixture of the dough, a percentage of ice water is used, usually provided by a Dose / Cooler. The finish is made of carbon steel with high resistance gray paint and stainless steel pan; the engine has two speeds with different speeds; time is controlled through a digital timer, allowing the operator to perform other tasks; the spacing between the basin and the column structure respects the dimension established by the NR-12 standard; low pan rotation at $15 \mathrm{rpm}$ and high at $30 \mathrm{rpm}$; low beater speed at $111 \mathrm{rpm}$ and high at 222rp. The Spiral Kneader can work with two different speeds, allowing the user to obtain a better performance.

Standardization for implantation of the Spiral Kneader: The NBR15734 of 09/2016 specifies requirements for safety and hygiene in Bakery Machines (Kneaders). This Standard establishes the safety and hygiene requirements that apply to the design and manufacture of kneaders with a bowl volume greater than $5 \mathrm{~L}$ and less than $500 \mathrm{~L}$, used in the bakery and pasta industry, to process various ingredients, such as flour, sugar, fat, salt, water and others. This standard measure the conditions of hygiene and safety of the machine's application, since it is a food processor it is essential that these requirements are properly respected the parameters. NR-12 -
Safety at Work in Machinery and Equipment, describes that the Spiral Kneader (Ordinance MTb No. 1,111, of September 21, 2016), has specific conditions of application, being its details within the perspective mentioned below:

a) Class 1 kneader: kneaders whose bowls have a volume greater than or equal to 131 (thirteen liters) and less than 701 (seventy liters);

b) Class 2 kneader: kneaders whose bowls have a volume greater than or equal to 701 (seventy liters);

c) Kneaders whose basins have a volume less than 131 (thirteen liters) and are certified by INMETRO are excluded from the application of this Regulatory Standard;

d) Basin: container designed to receive the ingredients that are transformed into dough after being mixed by the beater, which can also be called a pan or vat;

e) Basin volume: maximum volume of the basin, usually measured in liters;

f) Dangerous areas of the basin: contact zone between the basin and the support rollers, if any;

g) Beater: device designed to, by rotating movement, mix the ingredients and produce the dough, which can have different geometries and be called, in the case of kneaders, fork or arm;

h) Dangerous area of the beater: region in which the movement of the beater poses a risk to the worker, the risk being that of being trapped or crushed. (NR - 12, annex IV, page 01).

For this standard that describes the specification conditions for bakery and confectionery devices, it has projections that are incorporated and adjusted by NBR 15734, which highlights the machine's safety and hygiene parameters.

Safety in spiral kneading machines: For the safety of the machine installation, priority is given to the specific information of the device, or even of the company, such as corporate name, CNPJ, serial number, can be found on the back cover of the manual. Design Rules: This machine has been designed in compliance with NR12 Safety Standard. Electrical Scheme: To view the schematic of the electrical control, depending on the $220 \mathrm{~V}$ or $380 \mathrm{~V}$ three-phase voltage (PANIZ, 2020). Paniz (2020) describes how the risks of this equipment do not generate any risk to user exposure, but, as a safety parameter, the manual should be read to avoid problems during the installation and use of the equipment, keeping it close to the workplaces. . It is recommended never to remove the cable from the equipment by pulling on the cord, always taking the plug and unplugging it; never use extensions or adapters to connect equipment. Do not remove the center pin from the plug. For the safety of the operator and electrical components, it is recommended that the installation site be grounded. According to Article 198 of the CLT (Consolidation of Labor Laws), the maximum weight the worker can carry is $60 \mathrm{~kg}$ without harming his health. As for the limitations, install the equipment with a minimum distance of $50 \mathrm{~cm}$ between one equipment and another, to avoid overheating the engine, install the equipment in a place where there is no heavy traffic of people.

Spiral kneading machine installations: The procedures must be performed for the best safety of the user, the equipment must be installed in a very ventilated area, a flat surface; leaving a space of at least $15 \mathrm{~cm}$ around the equipment; the metal parts are heat conductive, so before starting any 
maintenance check that the equipment is completely cooled; observe if the mains voltage is compatible with the equipment. For proper operation, this appliance must be installed in a place with a temperature between $5^{\circ} \mathrm{C}$ to $25^{\circ} \mathrm{C}$. - Never use extensions or ' $\mathrm{T}$ ' to connect the equipment; the ground pin of the electrical cable cannot be removed, always use plugs for 20 A with a $4.8 \mathrm{~mm}$ pin according to NBR 6147. In order to obtain the necessary security, the conditions of the system's installations have to be observed, to corroborate with the guidelines, a single-line diagram is proposed, highlighted in figure 2, which consists of a technical drawing developed with specific software, such as AutoCAD, for example, this drawing graphically represents the electrical installations of the work, through which the architectural floor plan is made and the symbolism is defined by ABNT (Brazilian Association of Technical Standards).

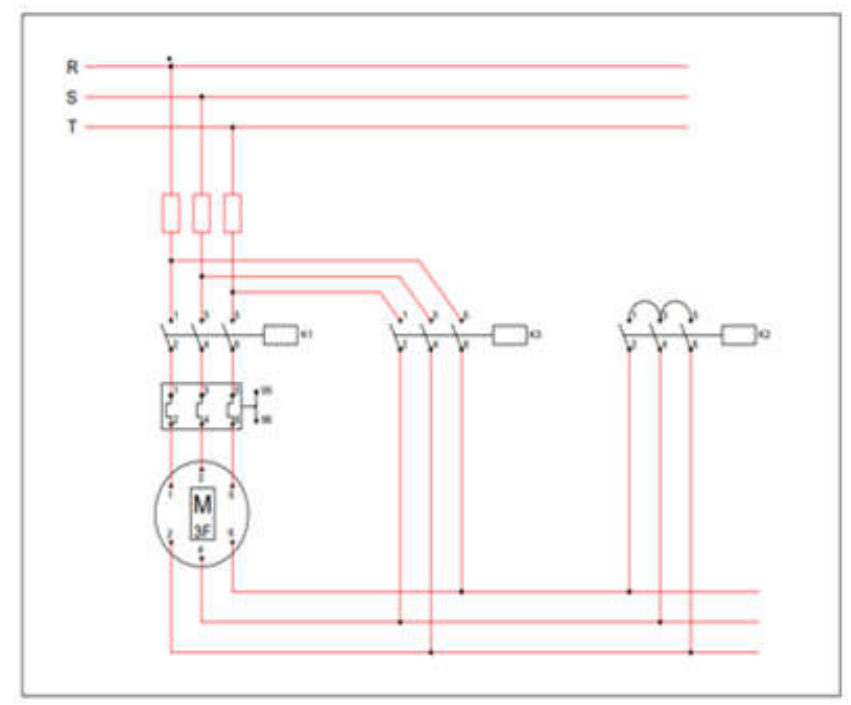

Source: The Authors, 2020.

Fig. 2. Single-line diagram that characterizes the layout of the work's electrical installations

This diagram is an adaptation condition that indicates the electrical factors of installation of the device, highlighting important points such as the dimensioning of the cables, the voltage and current of the system and the dynamics of the distribution of the force that drives the system, if well planned ensures stability and sustainability of the system in full operation. The differential in the process of an electrical installation is to correctly position the factors that will give sustainability to the device, for this reason factors such as the location of the elements, the paths, the conductors, how these loads will be distributed, the protection system and others, will giving the system a rigging condition. For this reason, the need for knowledge of the building's floor plan is of paramount importance for the proper dimensioning of the highlights and the Standards of ABNT's NB-8 drawings provides the installation conditions. According to SENAI (1996) the design criteria according to the Standard highlights:

"The location of the electricity consumption points, their commands and indications of the circuits to which they are connected; the location of staff and distribution centers; the path of the conductors and their mechanical projection (including dimensions of the ducts and boxes); a single-line diagram detailing the circuits, conductor section, switching and protection devices; the characteristics of the material to be used, sufficient to indicate the suitability of its use both in common cases and in special conditions." (SENAI, 1996, p. 04). As it can be observed the correct description of the insertion points of the devices must be properly detailed in the diagram proposed for the process, this reveals the concept that the operator visualizes the conditions of adaptability of the environment to the application of improvements, based on the regulations and the conception that the system has to work with stability, already foreseen in the diagram.

Hygiene in spiral kneading machines: As these are sanitary conditions for the operation of the machine, NBR 15734 determines the hygiene conditions of the device. Therefore, before cleaning the appliance, turn off the main switch and remove the plug from the socket, do not use metal accessories (knife, spoon and others) to avoid damaging the stainless-steel parts. Do not use plenty of water to clean the bowl, as moisture can damage the bearings. For external cleaning, it is advisable to use a damp cloth with mild soap, do not use a water hose as it may cause a short circuit and damage electrical components such as the motor and safety items. The cleaning of your equipment should always be done after its use, never use abrasive products, only neutral soap, as the device must not be cleaned with a water jet, the machine cannot be submerged for cleaning (PANIZ, 2020). The cleaning of the machine is important in the quality of the product being executed, and it is necessary that the protocols are duly complied with and followed in a standardized manner as specified by the manufacturer and the installation rules.

\section{MATERIAIS E MÉTODOS}

As for methodological procedures, according to Branski (2012) the case study is a research method that generally uses qualitative data, collected from real events, with the aim of explaining, exploring or describing current phenomena inserted in its own context. It is characterized by being a detailed and exhaustive study of a few, or even a single object, providing deep knowledge. According to Gil (1994), the choice of this method depends on the research object, focused on the parameters that the researcher wants to answer incorporating the three categories: exploratory, explanatory and descriptive, as a little-known phenomenon will be studied, it tends to identify the factors that collaborate with the elucidation of the phenomenon, explaining its cause, and the entire trajectory must be briefly described. For this work the importance of identifying the points that promote the correct way of implanting the machine, observing the conditions of safety and hygiene within the normative parameters of application and installation and use of the machine. The study was carried out in a company whose corporate name is called Padaria Lisboa LTDA, located at avenue Voluntários da Pátria $n^{\text {o }} 432$ Bairro Vila da Prata, Cep. 69.030-520, Manaus-AM, with Foundation dated April 21, 1985, with its Owners João Rodrigues de Matos and Sebastiana Maria Rodrigues de Matos, Brazilian, Born in Itacoatiara-AM. As the company acquired a superficial spiral kneading machine, having certain difficulties to make it work satisfactorily, due to technical implications, this study sought to accompany the process of identifying the standards, correcting the points of difficulty for implementing the technology within the possibilities on-site installation. For the development of the research, the case study method was used, following the steps: research design; research design; preparation and data collection; case analysis and article elaboration, as can be seen in Figure 3. 


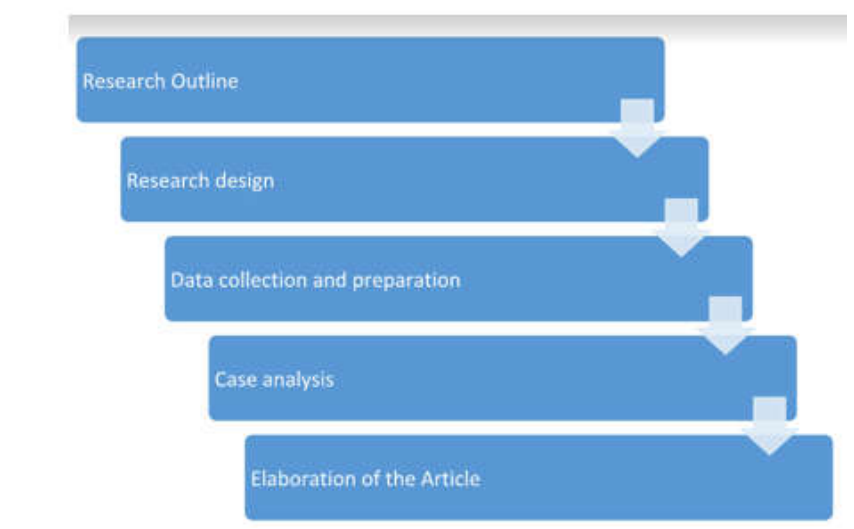

Source: The Authors, 2020.

\section{Fig. 3. Work structure, case study}

Within the work planning, the steps were performed through the research design that raises the problem conditions to be studied. Then the research starts to be mapped to define the points to be studied, on the threshold of the activities, it went to the field to visualize the conditions of the machine and collect information about the safety and hygiene situation and its proper installation. With the data collected with the standards and the impact factors on the application of the machine correctly the data are analyzed and discussed and positioned in the article presented here.

\section{RESULTS AND DISCUSSION}

We identified that with the implementation in the pan as: stainless steel coating, after some tests carried out before and after the implementation, we obtained very satisfactory results in relation to hygiene in the manufacture of the breads, as previously we did the same test and it was found that at each cycle of process for the manufacture of the breads it had to remove a small part of dough that was sewn on the inner wall of the pan, generating a waste of time from 01 to 02 minutes, for the generation of a new manufacturing cycle. Looking at figures 4 we also had other modifications and maintenance, all other parts of gears like; motor winding, pulley windings and grease from the lubrication reservoir that makes up the spiral kneader, have been changed so that we can have a better functioning of the machine. Based on regulatory standard 12 the first objective was to place a containment cover on top of the pan, thus interfering with the direct contact of the operator with the machine in operation, when the cover is opened, the entire circuit will be disabled through the 'magnetic key' that is interconnected in the safety relay which in turn will disable all electrical control and the machine it will only start operating again as soon as the cover returns to its origin and the operator rearms the entire circuit through the 'reset' button, in case of any undue eventuality the operator must activate the 'emergency' button. The spiral kneading machine proved to be challenging with regard to implantation in the location chosen for its application, due to the technical specifications that are necessary for its proper allocation.

The importance of studying the conditions of installations, safety and hygiene can be decisive so that the machine system can operate efficiently, there is no way to neglect the standards, because, as in this case, even though the adequacy procedures were observed, the system also presented factors that prevented the real functioning of the machine. The spiral kneader works using the physical principle that makes the blades rotate in synchronized movements to homogenize the dough. For this type of technology, safety is a very important requirement, since the control of the functions allows the commands to be activated and the assistance of the process can be observed directly, with the observation of the parts meandering in the mass aggregation space. In the situation of the machine of the study described here (Figure 4), it highlights its assembly on the support platform of the structure, making explicit the provision of an adequate space, factors such as the aeration of the environment is very requested by the need to not allow the machine to work in precarious conditions.

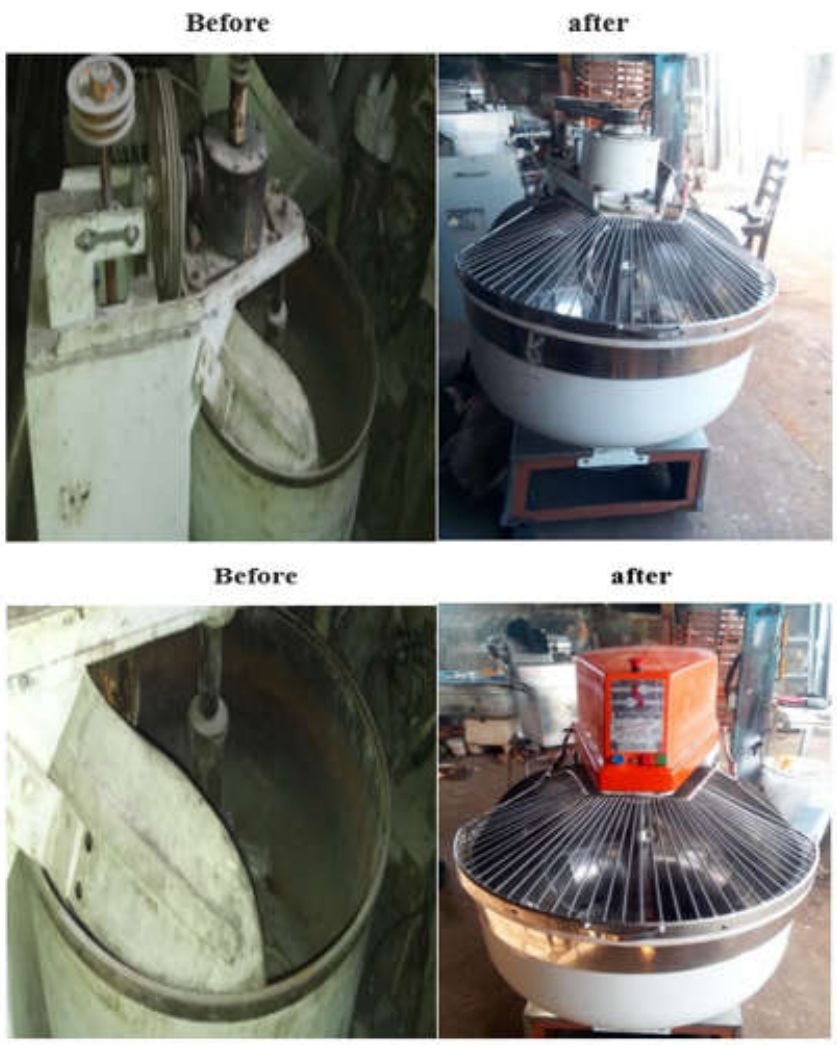

Source: The Authors, 2020

Fig. 4. Spiral kneading machines in an installation environment

Mediately even if the machine was installed in a ventilated environment, observing the technical standards, it was necessary to establish observation criteria, so that the sanitary inspection system can certify the system and authorize its operation. SCHNEIDER (2011) mentions that installing devices that act preventively in the occurrence of accidents, control and quality mechanisms for operations, minimizing risks, as the machines, when installed, must comply with NR 12 , as well as enable the proper installation of safety and hygiene factors, applying the methodology highlighted by the supplier in the chronological sequence in which a security system requires, thus the risk of problems is minimized. The machines are properly installed and their production logistics respecting the standardization of NBR 15734 and NR-12, which was analyzed for the first case, the safety conditions specifically for spiral kneading machines, following the protocol and the design of the steps that were specified by the manufacturer. With regard to hygiene conditions and how the process is to produce food on a large scale, this issue is more passive of observing the execution and compliance with the standards, so it was necessary to make a specification standard, study the conditions of application of the standard, the presence of a specialized technician was requested to raise the 
points in instability to supplant the necessary insertions. The realization of the study showed that the implementation of technological tools requires the incorporation of new methodologies to satisfy the needs of the new inputs, which includes the verification of food sources, hygiene and health condition, since the DSST - Department of Safety and Health at Work, coordinates nationally the inspection of hygiene environments, conditions and processes. The utilization phase is understood as the transportation, assembly, installation, adjustment, operation, cleaning, maintenance, inspection, deactivation and disassembly of the machine or equipment must always strictly obey the established conditions so that it does not cause problems with its use for the user end, for operators and others. The machine technology used in the industry has brought many advances to the production of goods and services, history reports the advance of machines and their ability to increase productivity, improve product quality and so on, generating new possibilities for society, a true revolution, but care for the environment, cost-effective conditions, always impact on the reality of these devices so current in our daily lives, technology advances to increase the reach of revolutions that come with the need to implement information impact on the application of inputs. As a result of the studies applied here, it appears that it is always possible to understand the working conditions to insert innovations in the field in which we operate, in this case, the entrepreneur who makes an investment and has the prospect of profiting from the innovation in the company and when the impact occurs of problems, the incorporation of standards that guarantee the improvement of the system should be planned. Technology is on the rise and information has to be the engine for monitoring innovations. For the study promoted here, it is clear that one must not forget to evaluate each stage of use, without forgetting to insert the definitions that support the regulation. For the installation of the spiral kneading machine to be consistent with the safety standard, the electrical system has to be properly thought out and planned as expressed in the Unifiliar diagram described in figure 2, which highlights the need for the projected electrical system to be able to predict the conditions ideals of functionality, since taking into account all legal aspects the chance of problems in functioning is attenuated. For this reason, the diagram must discriminate the appropriate commands, as shown in figure 5, which signals all the fundamentals of application of the electricity system for the functioning of the device.

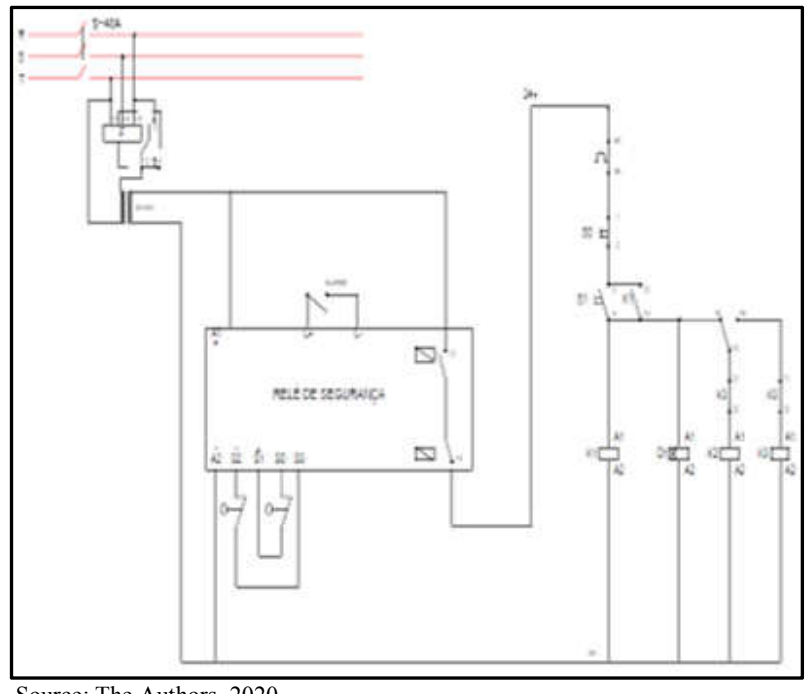

Source: The Authors, 2020

Fig. 5. Description of the electrical controls in the projected installation
The sequencing and the visibility condition of the sectors that drive the machine's power supply are fundamental so that, first, it fulfills the safety condition that the standard requires, second, that the system is viable and sustainable, as it is a machine which requires parameterized conditions, this mirror expressed in the diagrams is fundamental for its proper functioning. For the kneading machine installed at Padaria Lisboa, the instrumentation of technical factors was essential for the installation to be successfully completed and approved by the control system. The machine was duly inspected and its operation authorized within the standards, overriding the limiting factor, safety, as designed and executed the project within the normative procedures the safety factor became an extended condition for the entire environment, where the owner being Enlightened about the need to have the systems aligned and standardized, he understood that he should review some technical factors that hung in the Company. As for the hygiene condition, this was resolved by the adequacy of the environment, making a reorganization of the accesses and the sizing of the important points that complement the innovations. The intervention in the resolution of the problem at Panificadora Lisboa, highlighted that small factors, more important, can interfere in the quality of products and services, which is evident that in order to have balance and sustainability, the standards must be taken seriously, if it configures an apprenticeship, for professionals, as well as for the entrepreneur who was harmed by the lack of adequate information for the installation of a new device in his establishment. Thus, it is clear that the importance of technical information can solve risk situations preventively and, when this risk is already in progress, the dimensioning of the factors must be measured and corrected with all responsibility by the deployment team.

\section{Conclusion}

In the study shown here, it highlights the importance of observing the technology implementation rules, making clear the need to manage the coordinates that guarantee the credibility of companies within such a competitive market. Which seemed unnecessary, because to install a technological product inside a company, just follow the manufacturer's specification, but that's not the way it is. The environmental condition, the adaptation of the real factors of the location and other attributes such as safety, hygiene and others, are crucial points when inserting a product in the environment. The discussion and application of the rules to support the application of a device that modifies the operation of a factory requires that the implantation criteria are positioned to reconcile to the requirements and not run the risk, as in the case of Cervejaria Backer, even though it seems that all norms and specifications had been met, caused inconvenience to users, harmed businessmen and created a new chain of concern with quality, safety and health. The perspective with the accomplishment of this work was to discuss the procedures of surveillance and observation of the legal parameters for the realization and incorporation of new technologies, it is required that everyone involved in the system, which goes from production to the final consumer, be aware that qualities of the products will be satisfactory in the market. Technology is the spring that triggers better subsidies for production innovation, as in the case of the bakery industry, safety and hygiene are vital for the company's certification, customer satisfaction and adequacy of subsidies that support the reliability of services. There is no magic formula, there is a 
need to respect what is established in the standards and specifications, which ensures that in the globalized world, which is capable of sudden changes, it does not abandon the need to study the standards, verify the failures of operations and correct them. always acting to validate technology and its effects on society.

\section{REFERENCES}

AssociaçãoBrasileira de NormasTécnicas. NBR 15734: Informação e documentação: citaçõesemdocumentos: apresentação. Rio de Janeiro, 2016.

BRANSKI, Regina Meyer; Franco, Raul Arellano Caldeira; Lima Jr., Orlando Fontes Metodologia de Estudo de Casos Aplicada À Logística. UniversidadeEstadual De Campinas (UNICAMP), 2012.

CUPANI, Alberto. Filosofia da tecnologia: um convite. Editora da UFSC, 2016.

Gil, A. C. Como elaborarprojetos de pesquisas. São Paulo: Editora Atlas, 1994.

MARSON, Michel Deliberali. Origens e evolução da indústria de máquinas e equipamentosem São Paulo 1870-1960. 2017. Tese de Doutorado. Universidade de São Paulo.

NR-12 - Segurança no TrabalhoemMáquinas e Equipamentos. Anexo VI- Máquinas para Panificação e Confeitaria PortariaMte $\mathrm{N}^{\mathrm{o}}$ 197, De 17 De Dezembro De 2010. PortariaMtb N 1.111, De 21 De Setembro De 2016.
PANIZ. G. Amassadeira Espiral. Manual de Instrução e Termo de Garantia Segurança (2019). Disponívelem <file://C:/Users/aline/OneDrive/\%C3\%81 rea\%20de\%20T rabalho/paniz.pdf $>$ acessoem 03.02.2020.

PERFECTA. Especificação Técnica- AmassadeiraEspiral 80KG (2020). Disponívelem <file://C:/Users/aline/ OneDrive/\%C3\%81rea\%20de\%20Trabalho/188especificacao-tecnica-amassadeira-espiral-80kg.pdf acessoem 02.02.2020.

REGULAMENTADORAS, Normas. Segurança e Saúde no Trabalho. 2013.

SCHNEIDER, Elmo Ebanês. Instalações de dispositivossegurança para máquinasoperatrizesconforme a normaregulamentadora $\mathrm{n}^{\mathrm{o}} 12$ com ênfaseemdis positivoselétricos. 2011.

SENAI- Serviço Nacional de Aprendizagem Industrial. CPM Programa de Certificação de Pessoal de ManutençãoElétrica - DesenhoLeitura e Interpretação. Trabalhorealizadoemparceria SENAI / CST (CompanhiaSiderúrgica de Tubarão), ES, 1996.

SILVA, José Carlos Teixeira da. Tecnologia: Conceitos e Dimensões. XXII Encontro Nacional de Engenharia de Produção. Curitiba - PR, 2003. DOI: 10.14488/1676 1901.v3i1.616

https://www.ifsc.edu.br/documents/30701/523474/panificacao. pdf/3cecfb0b-9d70-be73-e4a8-c402890255e8. 